\title{
The Digital Bauhaus
}

\author{
GERARD SMULEVICH \\ Woodbury University \\ USA
}

This paper describes the use of electronic space in a fourth year undergraduate architectural design studio. It attempts to address the importance of developing a design process that is redefined by the use of computing, integrating concept and perception. This goal is set in the studio exercise, an international student design competition to design an addition to the school of architecture at the original Bauhaus/Weimar. The studio involved re-evaluating the Bauhaus principles of integrating the artist and the craftsman, but in contemporary or post-industrial terms. In 1989 the Wall came down. Seamless access of western telecommunications and media became greatly responsible for the crumbling of the rigid machine-age soviet technocracy; and with it, the former east German city of Weimar, home to the first Bauhaus, was once again a living part of architectural history. When the Association of Collegiate Schools of Architecture announced an international student competition to design a new addition to the school of architecture at the original Bauhaus/ Weimar, we immediately decided that this should be an Electronic Bauhaus.

\section{BACKGROUND : TOWARDS A NEW BAUHAUS}

The manufacturing-based society that emerged from W.W.I served Gropius et. al. to defy the stagnating rhetorical architectures of an un-democratic past. It was a meaningful stance especially because the machine had become instrumental in changing the world. The Bauhaus came to represent the aspirations of a mechanized New Order for the World, a proletarian one. There was no way but up, like Tatlin's spiraling tower.

These ideals were picked-up by the free-market W.W.II victors and adopted to identify the optimistic tomorrow of the fifties and sixties, riding the synergetic wave of optimism of the first nuclear age. By the late sixties the age of the machine had started to grind to a halt. Venturi's Complexity and Contradiction and Rossi's Image of The City were published and the Post Modern dilemma was upon us. The inspired ideal of the Bauhaus of uniting creative vision with the logic of making things had become obscured with a desire for a feel-good world modeled on better, pre-napalm times. The once groundbreaking New Technology that would liberate humanity from authoritarianism had effected all the changes it could, and its fading economic, spiritual and political force immediately started to give way to old doctrines in drag. Ever since the Bauhaus originally appealed to the ideal of the machine and industrialization as a means for reintegrating the arts into mainstream society, no other radical technological transformation occurred until the advent of Information Technology (nuclear energy proved to be a dud ). It was not until recently that a geopolitical/ technological broth like the one that was key to the original inventiveness of the Bauhaus was to be seen again. Gropius, Meyer, and Itten sought to embrace a technology that was instrumental in defining their economic and political environment, supporting the creation of a focused design philosophy and general attitude towards art, industry and politics. The elevation of the medieval artisan to modern industrialized design translated into becoming men and women of their time. We refer to this state as being modern.

\section{A DESIGN PROCESS FOR THE NEW WORLD ORDER}

Today, we do not celebrate our technological evolution as a benchmark of our societal accomplishments as did the society of the industrial revolution. The reason for this may be found in the fact that the product of contemporary technoevolution is immaterial, or in others words implied. It is in relative terms, materially transparent to our senses. This is why some have referred to it as a transparent technology.

The machine and the industrial process generated its own image, its own iconography. It defined an aesthetic for mass produced goods and spawned an immediate, irreducible architectural vocabulary. In seeking the material equivalent for information technology, we find ourselves stuck with ironically industrial age icons, such as television / ATM screens and Nine Inch Nails videos. The cloak of transparent technology uses known icons to suppress the post-human complexity of information manipulation. The design ideology of the pre-electronic era related very well to the industrialized notion of hierarchy and contiguity, that is, a principle of physical connection between program parts in buildings and cities that reflected the values and needs of the 
Machine Age; but in our post-machine age we must accept the discomforting reality that the world is much more complex through interconnectivity and fragmentation than it was when the Bauhaus was founded, and that the way we design our buildings and cities will reflect that, one way or another. The way we rethink our building programs will affect the ways by which we design them. It will affect the design process itself.

Our world's New Order, both geopolitical and technologically is progressing closer to Ridley Scotts' Bladerunner vision of accumulated layer over layer of history forming one great anarchic cyber-soup, rather than the replacementbased visions of the 1920's Fritz Lang nightmare of a machine-dominated, hellish Metropolis or the 1950's The Jetsons vision of a glistening and totally re-invented nuclear utopia. Acknowledging this transitional reality was crucial to our definition in the use of information technology in the studio. We know by now that use of computing in the design of buildings and cities is not going to simplify the practice of architecture at the push of a button; on the contrary, we are finding that there are only more and more variables and conditions in the design and construction process that renders the practice of architecture ever more complex. More is more, and there's more on the way.

For this reason, we must strive to develop a philosophy and process for the practice of architecture rooted in the dynamics of our current, emerging fragmented environment held together by electrons. If we want architecture to reinvent itself, as did the Bauhaus in its time, it must evolve on par with the rest of the creative and productive activities that define our world. We must relearn what it means to be modern.

Architecture has always been a discipline that entailed a need to know, control and define all the aspects and variables that affected the design process. We always had to feel safe, making bold manifestos and setting rules to distinguish right from wrong; but in the future, if we are to assume the responsibility of being active in the shaping of our physical realm, we will have to adopt a progressive attitude towards evolutionary change.

We will have to become comfortable with knowing that we will never know enough about information technology to become comfortable with it.

In this light, it is foolish to think that transparent technology allows for simply another more sophisticated way of designing the same buildings as done over the last 75 years. The consequences of such a conservative adaptation to transtech by architects is clearly seen in the wide spread tendency to use overdone computer generated renderings to describe boring, unimaginative and even bad buildings that convert the efficiency of information systems into a weapon of architectural mass murder.

This phenomenon could be placated if instead of seeking new ways to do the more of the same, architects acknowledged the newer technology as a natural expansion to the design process; an added electronic layer over the analogue past. As in Bladerunner, we should be seeking to add-on new strata to the old instead of pursuing the no-win chimera of replacing one process with another.

\section{FOREGROUND: THE STUDIO}

A core issue in the programmatic definition of the Electronic Bauhaus was to acknowledge the design process as the crucial stage where all architectural theory effects change. Walter Gropius and Johannes Itten dealt with a two ended design process defined by abstract spatial organization on one hand and empirical materiality on the other, under the notion of combining the artist with the craftsman. The Electronic Bauhaus studio employed these principles and attempted to redefine their validity by merging them, this time, in electronic space.

Our first premise was to understand these philosophical principles of the Bauhaus. Each two member design team was asked to identify original bauhausian pedagogical and theoretical notions that they felt had validity today. The effects of information and communications technology were compared to machine and industrial technology.

The second issue at hand was the study of the layering of technological evolution (its effects ) over a pre-existing, historically significant context as is in case of the city of Weimar. To establish these parameters as clearly as possible, video footage from a field trip to the Bauahaus/Weimar became valuable information for the studio, and a copy of the tape was available in studio $24 \mathrm{hrs}$. a day.

The third concern was the role electronic space would play in such a project. We agreed that a Bauhaus for the Age of Information should not only incorporate electronic media as a fundamental feature of both design concept and resolution, but that the concept itself be developed to a great degree within an environment (electronic) consistent with the idea of innovation and being, once again, men and women of our time.

\section{SLMULTANEITY}

Our basis for a design process for the Electronic Bauhaus competition was to explore the reconciliation of the abstract with the material, or rather Concept with Visualization.

"Concept and visualization are always simultaneous. Only the individuals' capacity to feel, know and to execute varies in degree and speed.....In a work of art the laws of the physical world, the intellectual world and the world of the spirit function and are expressed simultaneously..." These words by Walter Gropius, Idee und Aufbau des Staatlichen Bauhauses Weimar, 1923. The difference between Gropius' idealized definition of Concept and Visualization and our studio's use of it was that we actually made both the conceptual and perceptual instances simultaneous, in the unifying environment of electronic space.

Concept: In our interpretation of Gropius' statement, refers to the instances of the design process that employ varying degrees of abstraction to better study or analyze specific issues in the design process. In the design process of the Electronic 


\section{Simultaneity}

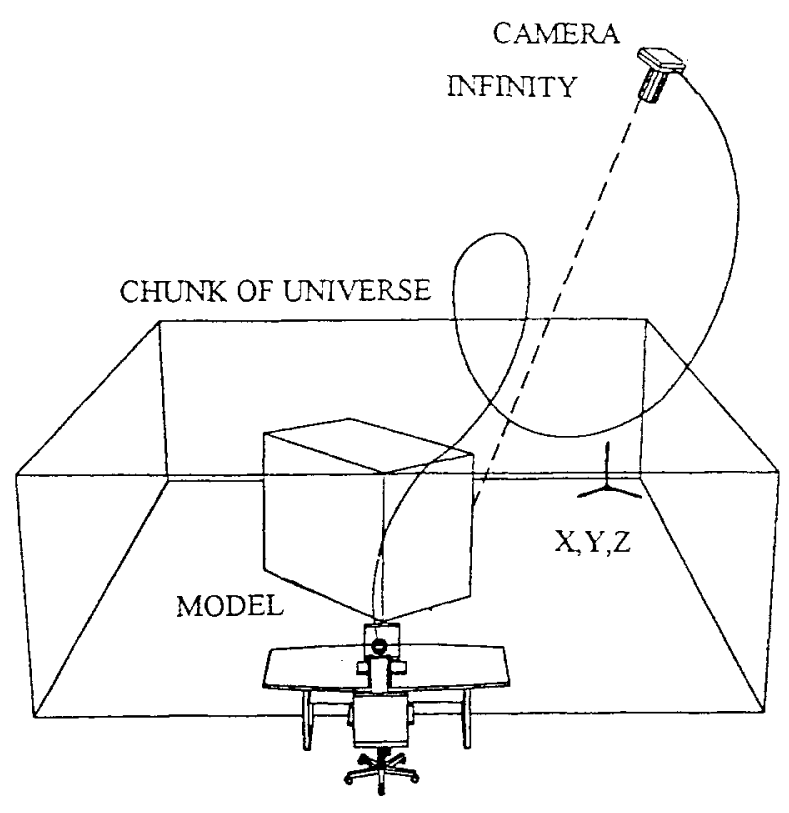

Fig. 1.
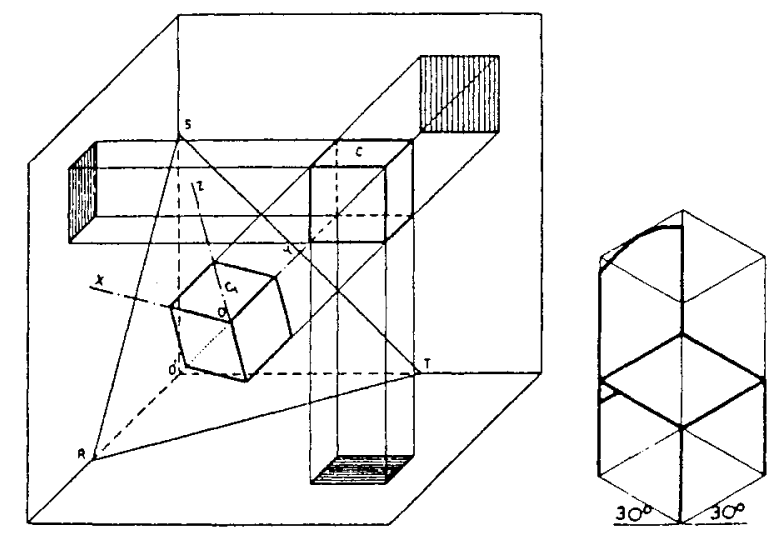

Fig. 2.

The Conceptual Instance: A non-experiential ( abstract) instance which can aproximate the appearance of an axonometric projection ( fig. 1), but is really a function of a very camera (electronic eye ) located at a very great distance from the electronic model, and not a simple two-dimensional decomposition of three-dimensional space, fig. 4. A plan would be interpreted as a special case of a conceptual instance.

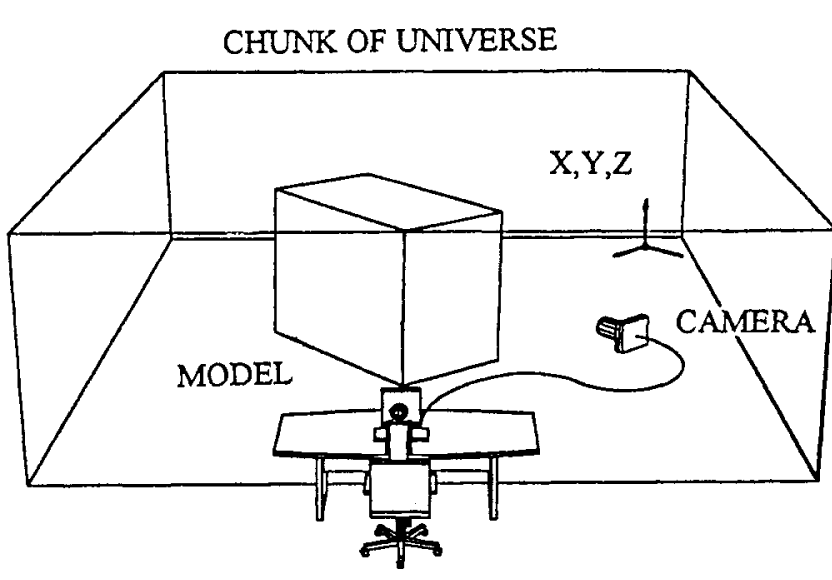

Fig. 3.

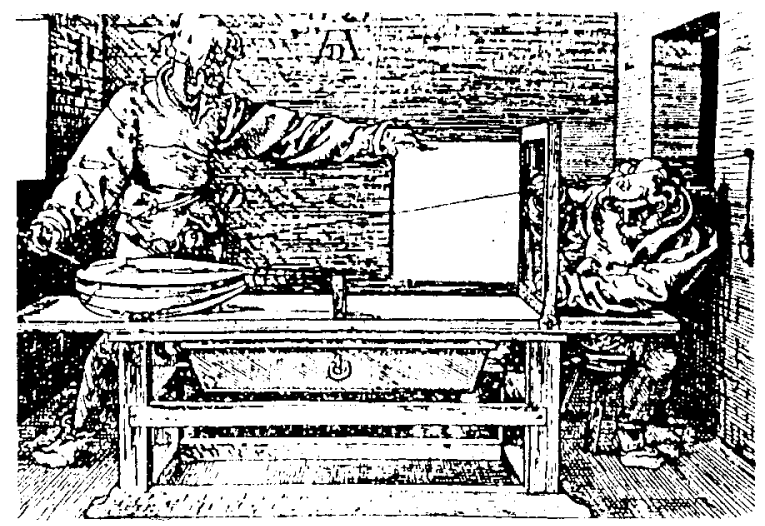

Fig. 4.

The Visualization Instance: A phenomenological state that is defined by the freedom to move through electronic space. It is defined by a highly mobile camera (electronic eye) that can explore the space of a full scale electronic model at will (much like exploring realspace with a video camera ), fig 3 . This is quite unlike a representational artifice, such as a perspective projection, here described by Albrecht Durer in 1525, fig 4.

Bauhaus, notions such as birdseye massing analysis, transparency studies, figure-ground and functional relationships were studied with the ultimate goal of developing the parti for each project. It was understood that as a competition entry, the basic idea or parti had to be clear and forceful.
Visualization: Seamlessly interacting with the conceptual instances of their processes, the students verified the experiential consequences of their analytical decisions. They used real-time walk-throughs as a means of studying their massing studies both from above as well as at eye level. Here 
the simultaneity that Gropius longed for became real, as we were moving in real-time through the space of an initial massing model experienced in full human scale. We were in fact enjoying a sensorial feed-back from an abstract concept, a partial instance.

Eventually, electronic inhabitation allowed the designers to truly understand the bearing of the historical context of the site, moving through gaps and nooks between existing medieval and nineteenth century buildings, assessing conditions related to scale, mass, and later on, materials and transparency.

One might argue that the architect's imagination and capacity to "see" space in the virtuality of the mind constitutes a valid instance of simultaneity in its own right; but this impoverished conclusion denies the opportunity to conceptually manipulate space while visualizing it. Our conceptual ideas and visions of space always have and always will be borne from the intelligence of our subconscious; but little do they serve us there. Our current ability to physically see and operate in real time on spaces projected from our own minds is definitively linked to our quest to inhabit electronic space. The opportunity to perceptually experience architectonic space at different levels of conceptual development constituted the most valuable and visible addition that $C A A D$ had to contribute to the design process of Electronic Bauhaus.

\section{THE COMPETITION PROGRAM}

The students' projects involved both re-using the original 1908 Henry Van de Velde building as well as using part of the adjoining the site for new construction. The competition problem also called for a master plan for a future campus that would include the expanded school of architecture. Certain buildings were to be preserved, such as composer Frank Liszt's house as well as several 19th century university buildings along a main boulevard facing a large park across the street from the site.The competition's sponsor was the Dupont Corporation, manufacturer of Butacite, a laminated glass, and the competition entries would be judged on the use of glazing in the design solutions.

The class built both an electronic and an analogue site model, to be shared among the three teams of two students each. It was clear that any media and form of architectural expression and communication was to be exploited as necessary. The combination of traditional and electronic modeling media become a rich, demanding and very productive process. One student on each team had some prior $2 \mathrm{D}$ or very basic 3D AutoCad knowledge.

The site analysis and context study was boosted by the instructor's field trip to Weimar, accompanied by faculty of the Technikum Winterthur of Zurich, and treated to a guided tour by Dr. Hans-Joachim Driefer of the HAB Weimar. The video and historical information retrieved provided the students with a crucial insight about the project's contextual reality and added yet another layer of complexity to the exercise. It also allowed them to address specific issues not described in the original competition literature, and incorporated later into the design process through electronic site modeling. Later, Michele Grendelmeier of Winterthur also provided remote critiques of student work in progress via fax Zurich-Los Angeles.

The first massing schemes attempted to address the conceptual issues of density and program distribution. For some students, the departure point for proposing a parti came from the original building and the site's very special physical characteristics; for others it came from formal references to original Bauhaus exercises or ideas, such as those espoused by Bauhaus master Vassily Kandinsky. All these studies involved real time walk-throughs as a means of incorporating the act of inhabitation as meaningful in pursuing the simultaneity of Concept and Visualization. To achieve this technically, we employed a Matrox Impression Pro video card with a proprietary AutoCad add-on called Dynaview. We had a total three PC's available, one of them owned by a student.

The instructor would help himself to a mouse and move through the fully shaded model at will. He would start up somewhere around 400 meters above the site, fly around looking down and then swoop down into a courtyard, moving across a catwalk-bridge and into a gallery space. Turning around, he would enter the Van de Velde building, go up to the third floor, and peek out a window into the courtyard separating the existing building from the new extension, and discuss with the students, for example how they might reassess the scale of a certain portion of curtain wall projecting too far into a courtyard or how a ramp that seemed appropriate in plan and section was really out of scale when electronically walking through the space.

Remarkably, studio desk crits were actually being held on-site. We actually talked about ideas and solutions while standing in a detailed electronic recreation of a building located nine time zones away. The complexity and number of issues we were able to address in this manner demonstrated the enhanced pedagogical capabilities of working in electronic space. One very important result noticed in the progress of the projects was the students' aggressiveness in incorporating the articulation of the ground plane as simply one more layer of space to be formed. With the subjective lack of gravity in cyberspace, it seemed that excavating down was no more restrictive than building upwards

The students were helping each other with the nuances of 3D modeling as a matter of survival. Hand drawings were always present next to the monitors. It was understood that computer modeling and spatial exploration were not to be used as an exclusive design environment, but as an addition to already mastered traditional design techniques. This hybrid approach acknowledged that the electronic media was relatively new to us, and we were not prepared to allow our lack of technical expertise to compromise our ultimate goal: To win the competition. In addition, we stood by the principle of identifying ourselves as architects of a society in transition, and as such we had no interest into being seduced into a false cyber-puritansim. 
The next phase involved the definition of program spaces, structural systems and materiality. Again, the design teams used electronic space to explore their options both conceptually and experientially. At this point we started to employ 3D Studio as our application of choice for desk-crit media, while still occasionally testing certain spaces in movement with Dynaview. By then, the projects' overall structural organization had taken form, and for the first time in the studio's progression, floor plans and sections were requested. We were four weeks away from the competition deadline.

One instance of the design process at this point was to create a transparency/ opacity study to determine areas of the projects that would use the competition sponsor's laminated glass product. This aspect of design approach benefited tremendously from the students' ability to inhabit the spaces electronically and actually see through the glass. Spatial layering and sight lines were studied in these instances. These exercises added a crucial level of credibility to otherwise abstract, wishful assumptions made by architects and specially students when trying to imagine a space as seen through varying degrees of transparency. The last nine days were dedicated to imaging and output.

\section{CONCLUSION}

The international student design competition for the Bauhaus/Weimar Revisited registered over 1,200 upper division and graduate students from 37 countries. Three prizes and three honorable mentions were awarded, and it was with great joy and a sense of accomplishment that we were informed that the submission made by students Natalie Magarian and Christopher Yanchar from our studio had received one of three honorable mentions for their effort. While it is hard to draw conclusions about an architectural design processes still in the making, we could state the following:

1. We found out that the immediate gratification enabled by visualizing ideas in electronic space certainly allowed more time for reflection and discussion on the basic principles and theoretical content of the design concepts. All the projects submitted had developed very strong, clear partis, and clearly expressed their political and theoretical stances. These qualities are crucial in a design competition.

2. The use of electronic media in our design studio was important, but we never forgot that that we were designing a chunk of city, and that our focus was in form, program and space and not on, screen resolution or amount of RAM. Systems expertise was unnecessary, and the students weren't focused on computers, only on architecture.

3. Most of the students started with borderline or no AutoCad experience at all; but all them had undergone a very basic Macintosh/Archicad drafting class a year before. For all their lack of formal training both in CAAD in general and in computer modeling in particular, they achieved an obvious high level of success in their projects. This proved to us that CAAD does not need to have a proprietary place in the schools' curriculum, becoming a specialty within architectural education; nor does platform specificity have any importance whatsoever. Students will find the necessary commands and techniques to achieve whatever it is they need to do on whatever platform they have available to them. It falls on the studio instructor help the students get by some hurdles in the use of electronic space as a design environment and not just as a visualization tool. It was the theoretical and practical notions of applied electronic media to the architectural design process that made a difference here, and not computing expertise. CAAD seems to belong in the design studio, and not in a detached computing laboratory.

4. Good projects were taken to depths of study usually not seen in a ten week studio. Our ability to experience firsthand inhabitation and incorporate perceptually accurate lighting and materiality to the solutions (thanks to the immediacy of electronic space) permitted concentrating the visual impact on the projects' use of glazing, turning the competition sponsor's concerns into an effective means of visual delivery.

5. The responsibility of learning the use of electronic environments has and always will fall on the users themselves; but all design faculty without exception must be well prepared in electronic modeling techniques and visualization if they expect to continue growing ( or working ) as design educators. Our studio found that we were running into a constant wall of misunderstanding and negative reviews from CAAD illiterate studio critics, and it became apparent that as long as computing was an issue in the design process, most guest critics were unable or unwilling to concentrate on the real issues of architecture in front of them. It was all to common to find more people willing to critique CAAD itself rather than architecture. These pre-concepts usually centered on surprisingly naive expectations of what they thought could or should be achieved by using computers in the design studio.

6 . While our intensive design process exploited the possibilities of electronic space to a high degree, there was no real emphasis placed on attempting to define an "electronic" architectural vocabulary. One question on our minds is: Should a building designed in cyberspace look any different than one designed on paper? The answer is probably yes, but not yet. This studio focused on a complex design problem, and did not have the opportunity to experiment in an aggressive alternative formgeneration technique outside of the competition's immediate goals; but that would clearly be the next step in this process. A logical step indeed.

7. Six students using three PC's over a ten week period produced the present body of studio work. We believe that spending several thousand dollars more on high-end workstations would have changed nothing.

8. The use of electronic space in the design process will 
allow for more and more personal exploration in the design studio as well as in the profession, as long as architects stop using electronic media as a means of perpetuating manufacturing-age dogmas and adopt a design process tied to the circumstances (and technology) of our time. Maybe then, architecture will become once again an initiator of change, and not just a consequence of it. As Lebbeus Woods stated in his monograph: Architecture is a political art: "One does not participate [ in the New World Order ] by following the crises of change, but by being part of its initiation."
9. It will not be technocratic systems expertise or computer savvy that will be decisive in the education of the next generation of architects; nor will the application of old doctrines with new tools allow architectural education to achieve parity with other forward-seeking disciplines. Rather, it will be unsettled and inquisitive attitudes that understand the evolving nature of our world and its dynamic relationship to our past. It will be an inclusive and multi-dimensional state of mind that will be influential in an evolution towards a new architecture. A state of mind that feels at home in the built realm as well as in cyberspace.

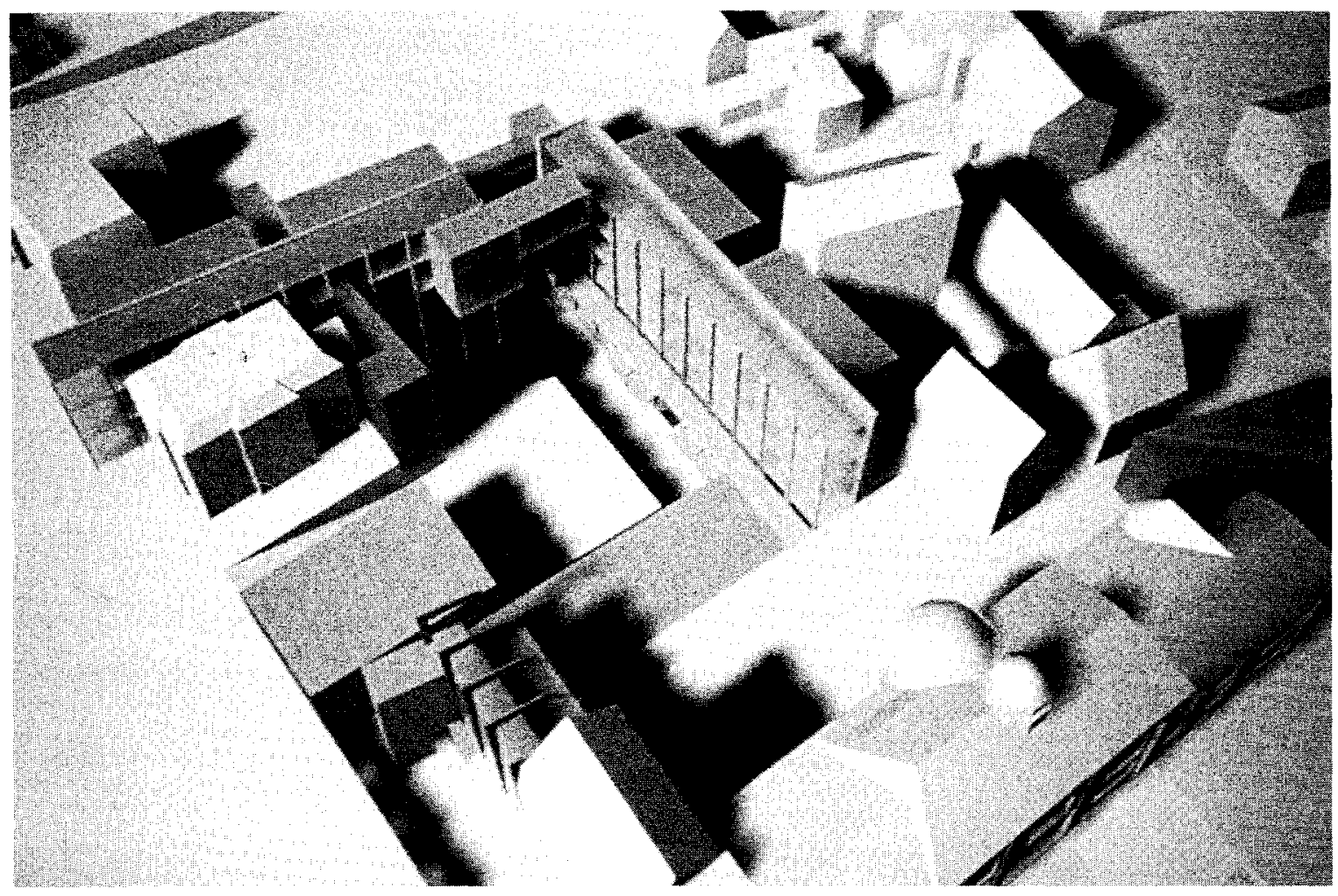

Fig. 5: Conceptual electronic model of addition to the Bauhaus/ Weimar. Sudents: Natalie Magarian and Christopher Yanchar. Studio instructor: Gerard Smulevich.

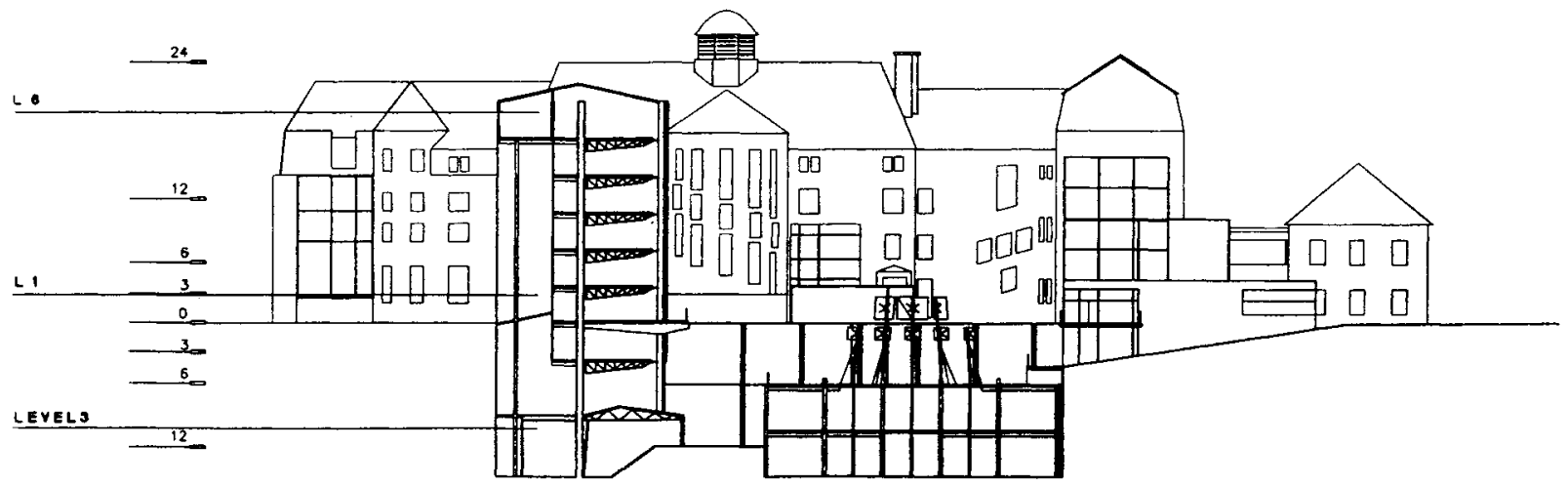

SECTION B-B

Fig. 6: Site section. Sudents: Natalie Magarian and Christopher Yanchar. Studio instructor: Gerard Smulevich. 

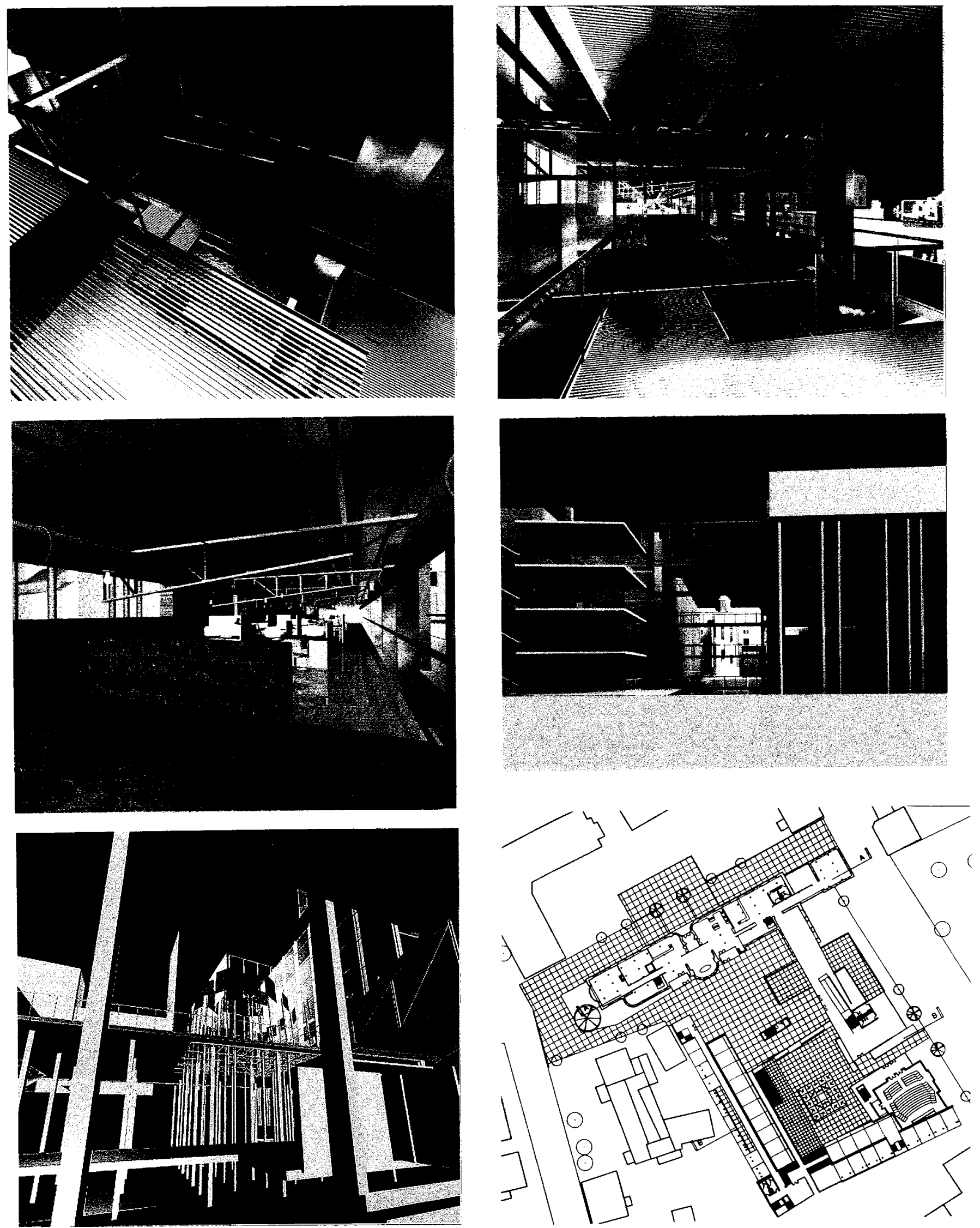

Fig. 7-12: Experiential images of electronic model and final floor plan. Sudents: Natalie Magarian and Christopher Yanchar. Studio instructor: Gerard Smulevich. 

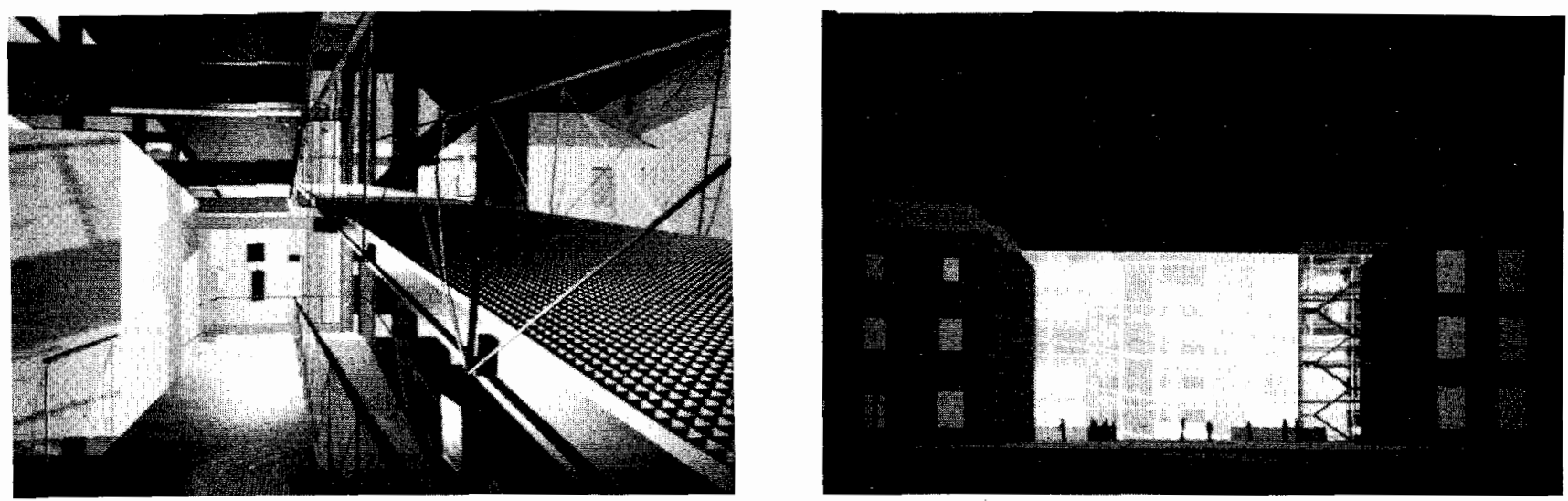

Fig. 13-14 : Students: Alexander Mijailovic and Brian Proffitt. Studio Instructor: Gerard Smulevich.
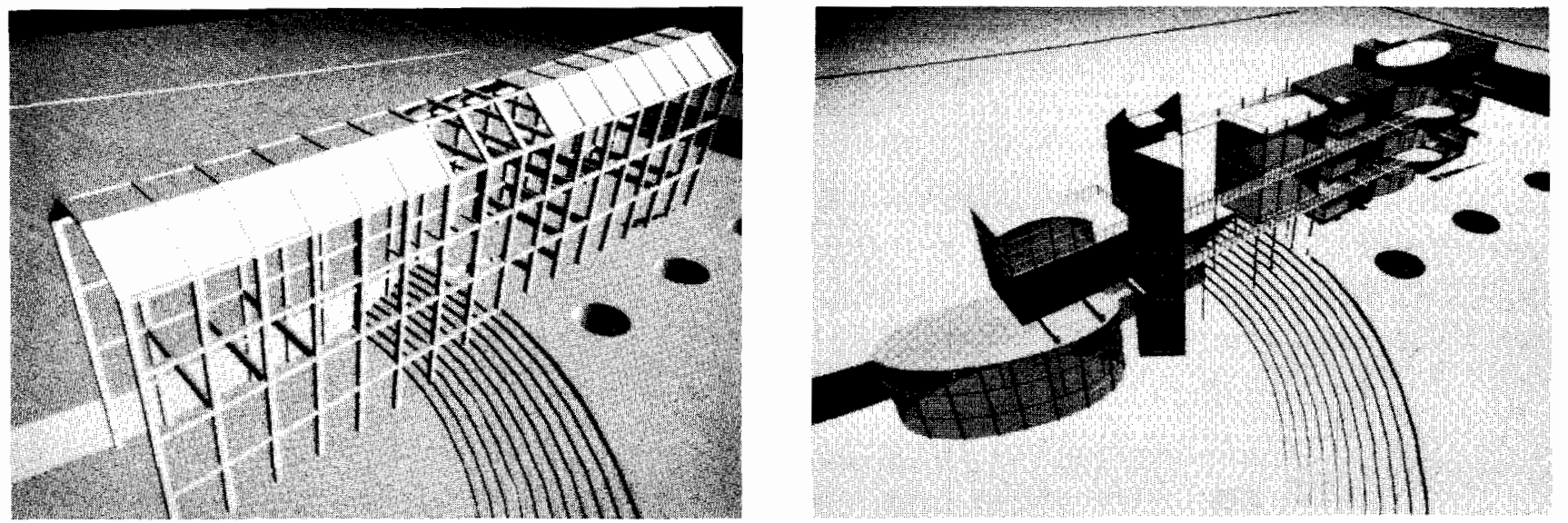

Fig. 15-16: Two stage conceptual study of exterior contextual shell and progtam-specific inner system.

Student: Brandee Dell'Aringa. Studio Instructor: Gerard Smulevich.
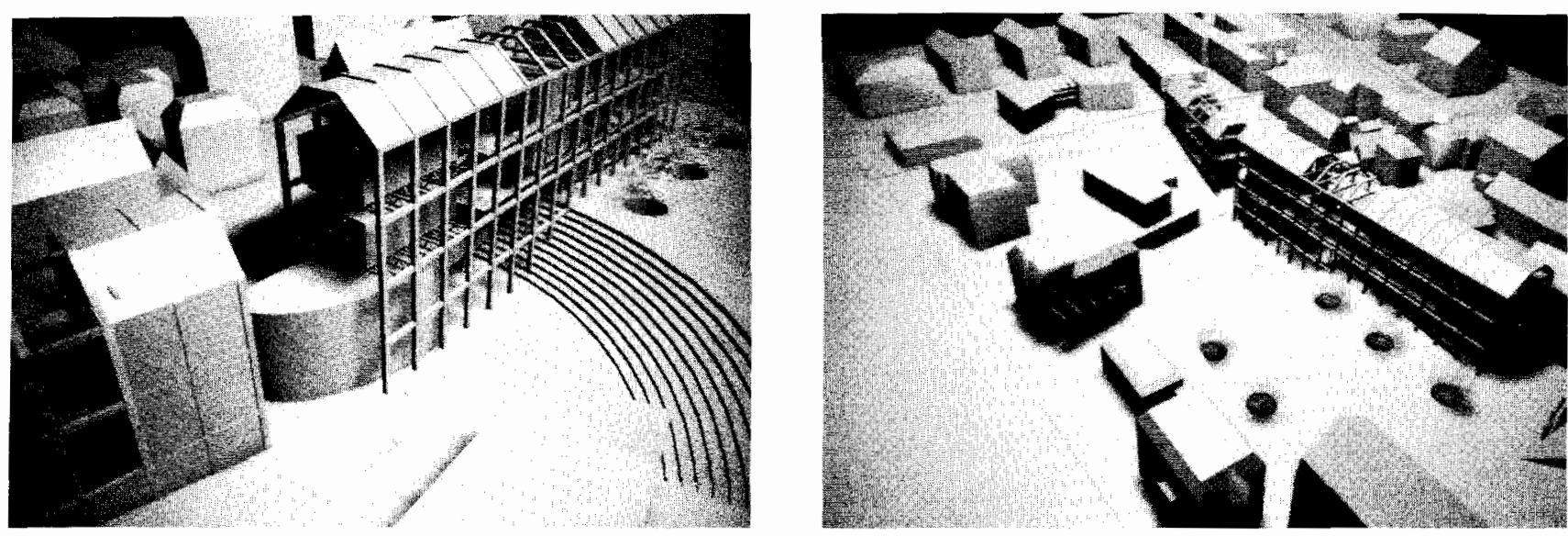

Fig. 17-18 : Conceptual views of electronic model. Student: Brandee Dell'Aringa. Studio Instructor: Gerard Smulevich.

\section{ACKNOWLEDGMENTS}

I wish to thank the following people:

Lou Naidorf, a.k.a The Dean, for his leadership, wisdom and uncoditional support for this project.

Professor Hermann Eppler of the Technikum Winterthur-Zuerich, for sharing his intelligence and love for architecture,and for showing genuine interest in our work.

Herta Eppler for giving the word hospitality a whole new meaning.
A very special thank you to Michele Grendelmeier and Jan, whom were instrumantal in making this project happen.

To Dr. Hans-Joachim Driefer of the HAB Weimar, for his time and patience.

I would like to extend my admiration, affection and respect to my students for the Bauhaus/ Weimer Revisited: Natalie Magarian and Christopher Yanchar; Brian Proffitt and Alexander Mijailovic; Brandee Dell'Aringa

To all you guys, you did a great job. 


\section{REFERENCES}

Frampton, Kenneth, "Modern Architecture, A Critical History," Oxford University Press, 1992.

Ehrlich, Doreen, "The Bauhaus," Magna Books, 1991.

Benedikt, Michael, "Cyberspace: First Steps," MIT Press, 1991. Gibson, William, "Neuromancer," Ace Books, 1984.
Lebbeus Woods, "Anarchitecture: Architecture is a Political Art." Architectural Monographs No. 22, Academy Editions/ St. Martins Press, 1992.

Smulevich, Gerard, "CAD in the design studio: The discovery of inhabitation," Association for Computer Aided Design in Architecture, ACADIA '93. Fred Morgan, Richard Pohlman, editors. 